\title{
Alimentação na escola e autonomia - desafios e possibilidades
}

\author{
School nutrition and autonomy - challenges and opportunities
}

Najla Veloso Sampaio Barbosa ${ }^{1}$

Neila Maria Viçosa Machado ${ }^{2}$

Maria Cláudia Veiga Soares ${ }^{3}$

Anelise Regina Royer Pinto ${ }^{4}$

1 Secretaria de Estado de Educação do Distrito Federal, Fundo Nacional de Desenvolvimento da Educação. 72000-000 Brasília DF.

najla.barbosa@fnde.gov.br

2 Departamento de Nutrição, Centro de Ciências da

Saúde, Universidade Federal de Santa Catarina.

${ }^{3}$ Instituto de Nutrição,

Universidade do Estado do Rio de Janeiro.

4 Centro Colaborador em Alimentação e Nutrição do Escolar de Santa Catarina.
Abstract This study seeks to emphasize school food as an important policy to promote student autonomy by means of food and nutrition education included in the curriculum, integrated with different actors and based on the standpoint of citizenship. It seeks to return to fundamental concepts in the context of school food reflecting on them through theoretical assumptions to identify possible strategies to promote citizenship and autonomy in school. The strategies involved food and nutrition education with the daily presence of quality and suitability in school meals, discussions on the various dimensions of food in the curriculum and integrating food in the pedagogical project extended to various areas of the education system. School food fosters the need for integration of actions, actors and the various social spaces interested in the food issue, such as ministries, education systems, departments and schools, so that they may tackle the demands of contemporary reality in an integrated, systematic, consistent and efficient manner.

Key words Autonomy, School nutrition, School, Curriculum, Food and nutrition education
Resumo Este estudo tem por objetivo evidenciar a alimentação na escola como importante política na promoção da autonomia dos estudantes por meio de uma educação alimentar e nutricional desenvolvida de modo curricular, integrado pelos diferentes atores e sob a ótica da cidadania. Retomar conceitos fundamentais no contexto da alimentação escolar, refletindo sobre eles por meio de pressuposições teóricas para identificar possíveis estratégias na promoção de cidadania e da autonomia na escola. As estratégias envolveram educação alimentar e nutricional com a presença cotidiana de qualidade e adequação na alimentação escolar, de debates sobre as diversas dimensões da alimentação no currículo vivido e com integração da alimentação no projeto pedagógico estendido a vários âmbitos do sistema de ensino. A alimentação na escola suscita que haja integração das ações, dos atores e dos diversos espaços sociais interessados pelo tema alimentação, como ministérios, sistemas de ensino, secretarias e escolas, de modo que se possa enfrentar, de modo integrado, sistemático, consistente e eficiente, as demandas da realidade contemporânea.

Palavras-chave Autonomia, Alimentação escolar, Escola, Currículo, Educação alimentar e nutricional 


\section{Introdução}

A proposta deste artigo é evidenciar uma reflexão sobre o conceito de autonomia e sua aplicabilidade no contexto da execução do Programa Nacional de Alimentação Escolar (PNAE) desenvolvido no Brasil. Essas reflexões, de maneira contextualizada, objetivam retraduzir e ressignificar esta política pública no universo local de sua execução, tomando por referência a potencial capacidade desse Programa em auxiliar e guiar os serviços e ações em saúde e educação.

O Programa Nacional de Alimentação Escolar, em seus princípios estruturantes, tem avançado em direção a consolidar o direito e o acesso à alimentação adequada e saudável no espaço escolar, promovendo e incentivando ações que se apresentam pautadas pelo pressuposto de que alimentação adequada não pode ser entendida e projetada a partir, somente, de seu entendimento estrito de adequação de alimentos por meio de sua composição nutricional, informando recomendações mínimas de energia e nutrientes.

Esta política pública, ao se inscrever enquanto parte do conjunto de políticas públicas sociais estruturantes, atuando especificamente sobre a questão alimentar, vem fortalecendo a sustentabilidade quando incorpora em suas defesas e princípios: a discussão da produção agrícola familiar sem o uso de agressores ao meio ambiente; a construção do saudável e da cidadania por meio dos cuidados promovidos pelas práticas de produção de refeições adequadas e seguras do ponto de vista nutricional, sanitário e da plena realização do direito humano à alimentação, por meio do fornecimento de refeições a todos os escolares. Dessa forma, o Programa se transforma em uma ação de política pública voltada para a construção da sustentabilidade, do respeito aos direitos humanos e da cidadania.

Nesta direção, também se desenha a importância da Educação Alimentar e Nutricional (EAN) no contexto do PNAE, não somente por desenvolver ações que garantam e assegurem a alimentação adequada em termos nutricionais e sanitários, mas por possibilitar, por meio de sua inclusão como parte componente dos currículos escolares, a integração dos temas Direito Humanos à Alimentação Adequada (DHAA) e Segurança Alimentar e Nutricional (SAN), ao processo de ensino aprendizagem desenvolvido na escola ${ }^{1}$.

Especialmente em relação à EAN e à sua inclusão como ação proposta pelo PNAE, considera-se importante referendar que, até o momento, o movimento histórico não projetou elemen- tos que conseguissem avançar em direção à discussão sobre a concepção do tema, o que coloca de imediato a necessidade de avanços no sentido de perceber qual a relação existente entre o alimentar, o nutricional e o educacional presente na proposta de EAN, para que o elemento educacional não seja secundário nesta discussão ${ }^{2}$.

Consideramos fundamental a retomada de pressupostos teóricos como estratégia metodológica para desnaturalizar ${ }^{3}$ conceitos como de autonomia e de direito à alimentação e, refletindo sobre sua utilidade na prática pedagógica institucional ${ }^{4}$, reinseri-los de forma sistematizada no contexto da alimentação escolar, de modo a identificar estratégias de enfrentamento e gestão dos problemas ${ }^{5}$. Pretende-se fundamentar uma prática transformadora na escola a partir de teorias atualizadas no contexto da educação. Sendo assim serão aprofundados os conceitos de autonomia, habitus nos termos de Bourdieu ${ }^{6} \mathrm{e}$ direito à alimentação, operacionalizando-os no âmbito da educação alimentar e nutricional nos dois últimos subitens do texto.

\section{A educação e o conceito de autonomia no processo educativo}

Nesse sentido, observa-se que a autonomia quase sempre aparece na literatura acadêmica vinculada à ideia de participação social e à ampliação dessa participação nas políticas sociais. Para o filósofo Rousseau, a discussão sobre o exercício da autonomia está diretamente relacionada à construção da democracia, uma vez que o pensamento democrático depende da liberdade e da autonomia dos indivíduos, ou seja, de como uma sociedade é capaz de reger suas próprias leis. Martins $^{7}$ assinala que, para o bom funcionamento da democracia:

"Não basta que um grande número de cidadãos participe, direta ou indireta, da tomada de decisões coletivas. Não basta, também, a existência de regras de procedimento como a da maioria, isto é, da unanimidade". Para o autor, tornase "...indispensável uma terceira condição: é preciso que aqueles que são chamados a decidir ou a eleger os que deverão decidir sejam colocados diante de alternativas reais e postos em condição de poder escolher entre uma e outra". (grifos nossos).

A ideia de que o acesso a alternativas reais compõe o leque de condições para uma efetiva democracia é extremamente relevante no debate da autonomia. Ou seja, não basta participar, é preciso garantir condições de escolha, e também opções e caminhos para esta. Entretanto, para 
melhor compreender-se como sujeito nesse processo, é necessário ao indivíduo conhecer sua realidade, as alternativas que dispõe, os direitos que foram conquistados em cada campo da sua atuação e as intervenções sociais necessárias para garantir que seus direitos sejam objetivados e ampliados.

Nesse sentido, o processo educacional constitui-se uma dinâmica favorável à construção desse perfil de cidadão que conhece, convive, pensa, transforma a sua realidade e reage diante das manifestações dela advindas.

Mas é importante considerar que não é todo processo educativo que contribui para a formação desse perfil. Ademais, vale ressaltar que esse é um perfil interessante para os que compreendem que as relações sociais serão tão mais humanas e construtivas de uma sociedade mais equitativa e digna quanto forem investidos os esforços na formação de um estudante e cidadão mais capaz de refletir sobre sua condição de sujeito na realidade social. Ou seja, está sendo afirmado que o grau de busca da escola e do professor pela autonomia dos estudantes determina o trabalho escolar e o processo educativo a eles oferecido e as atividades pedagógicas que consolidam esse fazer educativo.

Para Freire" "formar é muito mais do que puramente treinar o educando no desempenho de destrezas". Segundo esse autor, a formação do indivíduo abrange todas as dimensões da vida humana e o respeito à autonomia e à dignidade de cada um é imperativo ético e não um favor que podemos ou não conceder uns aos outros (...). Nesse sentido, o professor que restringe a curiosidade do educando, não aguça seu gosto estético, não estimula a inquietude, não o empodera na linguagem, que ironiza ou diminui o seu potencial, não contribui efetivamente para a formação dos estudantes e torna-se transgressor dos princípios éticos da nossa existência. De igual forma, age o professor que se exime do cumprimento de seu dever de propor limites à liberdade do aluno, que se furta ao dever de ensinar de estar respeitosamente presente à experiência formadora do educando.

Fica caracterizado então, pela sequência das ideias que temos desenvolvido, que a escola como espaço de construção da autonomia constitui-se um empoderado local de apresentação, debate e construção das alternativas, das várias possibilidades que o indivíduo, como cidadão, encontra ao longo da vida, no enfrentamento dos seus desafios. É esse o paradigma de educação que está adotado neste texto: uma educação em fa- vor da formação de indivíduos realmente autônomos, capazes de criticar e de propor alternativas diante da sua realidade.

\section{E a escola, que espaço é esse?}

Certamente, um espaço extremamente complexo e desafiador, onde, dentre as muitas práticas escolares, está a alimentação escolar. Esta atividade em quase a totalidade das escolas é cotidiana, acontece nos mesmos horários e com uma cultura de preparação, distribuição e consumo bastante particular da escola. Há aquelas em que os estudantes comem com o prato sobre a mesa da carteira, outros em que comem em refeitórios, outros ainda em pé e há também os que, por opção, não se utilizam desse serviço. Há um cotidiano. Baseando-nos em Bourdieu', pode-se afirmar que há um habitus que se institui no espaço escolar relativo à alimentação que ali se oferece.

Freire $^{10}$, numa perspectiva do cotidiano em nossa cultura, contextualiza nas discussões sobre alfabetização a problemática da desigualdade social, afirmando que "com as palavras o homem se faz homem”. Nesse sentido, afirma que discutir o cotidiano implica discutir a prática discursiva que não é somente uma forma de dominar a língua portuguesa, mas, sobretudo, uma forma de empoderar a si mesmo e ao outro. Para Freire, o discurso produz sentidos para as pessoas em seus contextos sociais.

E nossa questão passa por pensar sobre o cotidiano, a cultura e o habitus que se institui na escola: como o estudante percebe o alimento que lhe chega todos os dias? Ele sabe de onde vem, quem comprou, de onde comprou, quem selecionou, por que selecionou, sua importância para a manutenção de sua saúde? O estudante, lamentavelmente, não tem ainda o hábito de pensar sobre isto. Os profissionais da educação nem sempre estão devidamente informados.

Na sociedade moderna, a escola pode ser concebida como um espaço que privilegia o repasse dos conhecimentos necessários à manutenção do desenvolvimento social e econômico da sociedade, adaptando e acomodando os sujeitos a uma realidade social que se desenha como dada, sem leituras críticas relativas ao modelo como pode, preferencialmente, se constituir um privilegiado espaço de construção da autonomia, de análises críticas e produção de conhecimento e informação, onde a educação se consolida como prática social ${ }^{11}$.

Os educadores críticos defendem a escola voltada para o estabelecimento pleno de uma 
relação social onde comunidade, família, educandos e educadores possam refletir e empoderarse de argumentos e em favor de alternativas, ações e políticas voltadas para a sustentabilidade e para o respeito aos direitos humanos, o que a consolidará como uma escola competente, democrática, autônoma, séria e cidadã ${ }^{12}$. Nesta proposta de escola, emergem as possibilidades de que temas como direitos humanos, cidadania, sustentabilidade, ecologia, direito à alimentação adequada, entre tantos apareçam no currículo de forma integrada com outros saberes que são tradicionalmente reconhecidos como pertencentes ao cenário educativo. São temas que, se articulados, possibilitam tanto aos educandos/as e educadores/as a discussão da realidade e a viabilidade de propostas de construção de uma sociedade mais humana e cidadã.

$\mathrm{O}$ alimento e a alimentação, temas principais desse debate, no espaço escolar assim organizado, certamente serão desenhados tanto pelo entendimento de sua composição e qualidade nutricional quanto, principalmente, como elemento fundamental na continuidade da vida e reprodução da espécie humana, como parte histórica do viver humano. Nessa perspectiva, o alimento retoma sua característica de elemento constitutivo do mundo que se relaciona com a economia, com o capital, com a saúde, com a cultura, com o trabalho, com o prazer, com o sabor, etc. Ao ser identificado como tal, possibilita o empoderamento dos seres humanos de suas condições de sujeitos autônomos, protagonistas responsáveis pela construção de uma sociedade cidadã, que convive com toda essa teia de relações ${ }^{13}$.

Ao trazer esta prática para o espaço escolar voltado para a construção de uma proposta educativa pautada pela autonomia, não se pode desenhar somente uma prática centrada na relação alimentos e seus nutrientes. $\mathrm{O}$ alimento e a alimentação ao se apresentarem como elementos pedagógicos no espaço escolar, compondo propostas efetivas envolvidas com o currículo, poderão propiciar discussões que avançam em direção a análises mais ampliadas da realidade social e possibilitar o entendimento do espaço escolar como favorecedor de ações transformadoras da realidade social ${ }^{14}$.

\section{A construção conceitual do direito à alimentação adequada na escola}

Nesse espaço de atuação social, encontramse sujeitos que têm legalmente instituído o direito humano à alimentação adequada - DHAA, que se articula com a questão da segurança alimentar e nutricional e que perpassa sua história de vida e de sua família. O usufruto do direito à alimentação adequada é um processo de construção social, sobretudo numa perspectiva do que Freire considera como sendo a ressignificação que o sujeito faz a cada momento. A sensação de que o direito é uma lei capaz de se estabelecer como prática é ilusório no sentido de que o legislativo é somente uma das dimensões desse direito na vida, entre tantos outros instituídos. O usufruto do direito não e uma automação no contexto social. É necessária uma ética nesse processo de construção cotidiana, é preciso desenvolver a cultura do direito, o habitus que o institui como parte do cotidiano.

Uma cultura do direito envolve as possibilidades que tem o sujeito de conhecer e escolher os alimentos. A essa capacidade de optar entre as alternativas existentes, de maneira instrumentalizada, consciente e deliberada, se pode chamar de autonomia, como sendo a liberdade de escolha diante, inclusive e sobretudo, dos apelos da grande indústria na mídia, diante da ruptura com hábitos alimentares anteriores e não saudáveis. E tem que ser muito consciente porque a mídia contrata inteligências para impor hábitos e alterar o habitus das pessoas. Os adoçantes dietéticos e alimentos "diet", por exemplo, em poucas décadas mudaram sua imagem passando de alimento refinado e caro próprio para camadas médias e altas da população, para alimento popular e de baixo custo usado como terapêutica em nome da prevenção de obesidade. Qual sentido há em comer um alimento light? O que está implícito neste enunciado?

O momento é de construção de verdades relativas que se modificam de um contexto para o outro e que demanda interação social, criatividade e respeito às diferenças. Os fundamentos conceituais, a construção coletiva de conhecimentos e o acesso a informações orientam a construção dos significados dos sujeitos e ampliam suas possibilidades de viver e de entender a realidade dos diferentes discursos produzidos na vida social.

Se não se reconhece o poder do discurso que domina ou muitas vezes paralisa os sujeitos no campo social, sobretudo na escola, há um grande risco de manutenção dessa escola inflexível, fria, mecanizada e mecanizadora, quase sempre apática aos problemas e demandas da realidade social. Convém lembrar que seres mecanizados reagem sem pensar e se mantém alienados de si mesmos, ignorando seu potencial criativo. Para ilustrar, pode-se pensar: como a escola se comporta dian- 
te dos altos indicadores de mortalidade por doenças crônicas não transmissíveis, adquiridas quase sempre por meio de uma alimentação inadequada, como a hipertensão, a diabetes e outras? Como a escola reage diante da não aprendizagem ocasionada pela anemia e por outras doenças relacionadas à alimentação? Haveria alguma reação de indignação que se traduzisse em políticas e ações pedagógicas? Certamente que sim.

Pensar sobre os conceitos de direito e de autonomia pode representar uma estratégia para evitar o mecanicismo que é capaz de tornar as ações em torno da alimentação escolar mais conscientes e instrumentalizadoras e ainda modificar as práticas sociais estabelecidas, possibilitando que os estudantes passem da condição de meros reprodutores desumanizados a sujeitos autônomos, atuantes diante de sua realidade.

\section{A educação alimentar e nutricional como estratégia de construção da autonomia}

Na teoria de Bourdieu ${ }^{6}$, os conceitos são continuamente reconstruídos e operam como instrumentos que podem iluminar elementos invisíveis do discurso e do universo simbólico e imaginário. Nesta perspectiva teórica das ciências sociais, segundo Luz ${ }^{15}$, os conceitos operam como instrumentos de análise, coerentes numa representação esquemática da realidade, e ainda que logicamente estruturados, não deixam de ser uma interpretação dela. Segundo Carvalho et al. ${ }^{16}$, a comida pode operar como uma categoria de análise porque representa uma riqueza para o homem e é capaz de expressar, ao longo da sua história, a constituição das estruturas sociais desde o momento em que ele se diferenciou dos outros animais, ao prepará-la e socializá-la, dividindo o trabalho para consegui-la. De algum modo, o homem deve consumi-la refletindo, reconstruindo, desnaturalizando conceitos e concepções.

É necessário desnaturalizar a alimentação na escola como parte de uma rotina comum, automática, sem importância social. Desnaturalizar é estranhar aquilo que parece natural, é conhecer em detalhes o modo como foi se tornando natural, compreender quais são os elementos que dão força e poder a esse caráter natural nos conceitos, que os coloca em um lugar de verdade indiscutível.

É necessário estranhar que uma prática como alimentação na escola passe despercebida e seja tida com a mesma consideração que uma carteira, uma torneira ou um livro. Estranhar, neste caso, significa trazer o tema alimentação na escola para a mesa de debate.
O Programa Nacional de Alimentação Escolar constitui-se uma ação política que favorece pensar concepções e conceitos que engendram práticas em torno da alimentação escolar tanto no que diz respeito às ações estratégicas para SAN quanto às políticas educacionais. Segundo o Censo Escolar de 2011 do Instituto Nacional de Estudos e Pesquisas Educacionais Anísio Teixeira $(\text { INEP })^{17}$, estão matriculados na educação básica cerca de 42 milhões de estudantes; todos atendidos, em tese e cotidianamente, com uma ou mais refeições. De algum modo, mobiliza em torno do ato de alimentar-se na escola, quase um quarto da população brasileira.

Se bem for observada, a vida social na escola se organiza em conjunto com a alimentação, não somente como expressão das estruturas sociais, mas também como uma criação histórico-cultural capaz de convencionar a atribuição de significados que possibilite a comunicação. A alimentação pode operar como um tipo específico de linguagem que nos permite pensar sobre ela.

A legislação atual que define o PNAE, Lei $11.947 / 2009^{18}$, estabelece dois eixos de ação igualmente importantes: a oferta de alimentação escolar e as ações de educação alimentar e nutricional. Esta legislação abre precedente para se pensar que a parte tradicionalmente conhecida do Programa, a oferta de alimentação na escola (por quase cinquenta anos vinculada à assistência), passa a sofrer a influência de uma outra ação que a torna mais significativa e abrangente. De modo objetivo, sinaliza que a comum prática de comer na escola deve se dar ao mesmo tempo que a prática de educar para o ato de comer, tanto dentro quanto fora da escola.

Nesse sentido, vale refletir que as práticas de alimentação podem ser compreendidas como um núcleo de significação complexo, uma expressão sociocultural de significados que (re)produz códigos de identificação para as pessoas em seu contexto social. Comer é uma experiência social que envolve trocas simbólicas, acordos e negociações constantes sobre o significado dos alimentos em uma cultura.

Dessa forma, os significados do direito a uma alimentação adequada são construídos socialmente na realidade local, e podem ser potencializados com processos de educação alimentar e nutricional capazes de motivar e de dar sentido às ações entre os agentes da escola, de acordo com as condições que cada um desenvolve, para compreender o direito à alimentação saudável e adequada e as implicações desse direito sobre a segurança alimentar e nutricional numa dimen- 
são ética em favor da autonomia e do empoderamento do sujeito.

Para avanço nessa perspectiva, é importante considerar a instauração de processos claros, definidos e planejados de educação alimentar e de educação nutricional dos estudantes na escola.

\section{De que EAN estamos falando?}

Diante da conjuntura social contemporânea, é importante registrar a complexidade das ações humanas e a necessidade de alternativas criativas para enfrentamento dos problemas de nosso tempo.

Há uma crescente demanda social pela reflexão e ação sobre temas que assegurem maior conscientização acerca dos fenômenos sociais vivenciados e que permitam a possibilidade de investigá-los, sobretudo, quando se manifestam no sentido de inibir a cidadania.

Voltando o olhar para a escola, se pode perceber que os padrões rígidos de ensino e aprendizagem dos séculos anteriores hoje dão lugar a um debate sobre o perfil do estudante que se deseja formar e o papel do currículo escolar, buscando uma concepção de currículo para além de um desenho com poder de aprisionar e reduzir os conhecimentos da cultura humana em modelos inflexíveis que devem ser transmitidos de geração a geração. A grade curricular tem dado lugar a uma construção coletiva das ações e trabalhos pedagógicos a serem desenvolvidos na escola, a partir das demandas reais ${ }^{19}$.

Buscando um novo alinhamento conceitual, o currículo é uma ferramenta imprescindível para se compreender os interesses que atuam e que estão em permanente jogo na escola e na sociedade $^{20}$. Nesse sentido, adotamos aqui o conceito de currículo como conjunto de ações que cooperam para a formação humana em suas múltiplas dimensões constitutivas ${ }^{15}$. Esse entendimento faz referência ao complexo processo sociocultural que fez da escola um dos mais importantes meios de compreensão e reprodução dos conhecimentos produzidos pela humanidade.

Discutir o currículo é, portanto, debater uma perspectiva de mundo, de sociedade e de ser humano, uma vez que o currículo expressa relações de poder, ideologias e culturas. Nesse sentido, este debate não se reduz a uma visão tradicional de mudanças de conteúdos dos currículos escolares e sim a uma nova postura pautada na autonomia e na emancipação humana dos estudantes por meio dos saberes e práticas construídos na escola.
Nesse alinhamento, a educação alimentar pode perfeitamente compor o currículo escolar. Mais do que isso, pode ser desenvolvida sem qualquer prejuízo aos saberes consagrados nos conteúdos escolares. Ao contrário, irá agregar valor a estes conhecimentos, uma vez que permite, na análise real de cada indivíduo, instrumentalizá-los no entendimento da sua condição de ser vivo, das dimensões éticas, socioantropológicas e biológicas de sua existência, e que come e habita no espaço social.

Numa análise mais ampla, lamentavelmente, a organização que ainda prevalece em alguma parte das escolas remete-nos a uma concepção obsoleta de educação, de homem e de sociedade, onde o conhecimento é algo a ser transmitido, a aprendizagem é um acúmulo de informações, os conteúdos escolares são recortes arbitrários do conhecimento científico, os professores são seres encarregados de transmitir esses recortes e os alunos são seres que devem assimilá-los, em um contexto de recompensa ou punição.

No entanto, no Brasil, há diversas escolas que desenvolvem atividades que extrapolam seus muros e as transformam em efetivos "centros de formação da cidadania”, como prevê a vigente Lei de Diretrizes e Bases da Educação Nacional. Nesse processo, o entorno cultural da escola vira escola, ou seja, fonte concreta de pesquisas, aprendizagem e descobertas. Transforma-se em laboratório de experiências, fomentando as mútuas intervenções de alunos, professores, comunidade e produzindo as alternativas que podem interferir na qualidade social de vida de seus membros.

No entanto, para isso, é imprescindível parar e pensar sobre os caminhos e as alternativas didático-metodológicas possíveis para ampliar e potencializar os saberes e as vivências na escola. Nenhuma escola que avançou em suas práticas o fez sem esse redesenho coletivo do trabalho escolar.

Possivelmente, essa compreensão coletiva constitua um dos maiores desafios dos sistemas de educação no Brasil: construir uma concepção de ação educativa que atenda as múltiplas dimensões formativas do indivíduo e consolide a compreensão de que o currículo escolar se manifesta como expressão efetiva da vida vivida, em contraposição à ideia de um "currículo prescritivo", previamente elaborado e comprometido com a classificação e a acumulação de informações mecanicamente absorvidas e quase utilizadas.

Do ponto de vista pedagógico, para que o processo de educação alimentar seja efetivo e alcance os resultados almejados, algumas reflexões e ações parecem desejáveis para fortalecer a in- 
serção de tema alimentação escolar na prática cotidiana da escola, entre elas:

A) A alimentação escolar, que deve estar presente todos os dias letivos na escola com qualidade e adequação nutricional, conforme direito constitucional do estudante e obrigação do poder público, por si só representa uma estratégia pedagógica eficiente para trazer a evidência todos os infinitos assuntos e temas que o ato de alimentar-se fomenta. Para isto, todas as áreas do conhecimento são chamadas a contribuir: a matemática, as ciências da natureza, sociais, as artes, a linguagem, a história, a química, a física, a filosofia, e todas que vierem a compor do dia a dia da escola.

B) Os temas e os debates sobre alimentação devem garantir que todas as dimensões dessa ação humana sejam abordadas: a dimensão econômica, social, cultural, religiosa, psicológica, pedagógica, nutricional, artística, gastronômica, entre outras, dinamizando as ações do currículo vivido;

C) Embora não seja tão simples como parece ser, é importante que o tema alimentação componha o projeto pedagógico das escolas, direcionando atividades transdisciplinares entre os docentes e demais profissionais na escola, promovendo atividades integradoras da ação escolar e atividades fora da escola que ampliem a percepção e a leitura desse tema por parte dos estudantes;

D) As práticas de educação alimentar não são apenas as pedagógicas que acontecem em sala de aula. Essa educação deve acontecer nos vários níveis da política e em vários âmbitos dos sistemas de ensino. Parece interessante pensar que não é só o estudante que precisa ser educado do ponto de vista da alimentação, mas gestores, professores, cozinheiras, agricultores familiares, nutricionistas, coordenadores pedagógicos e também os seus pais. Por isso essa ação é abrangente e organizadora de muitas possibilidades de atividades.

Por todos os temas enunciados nesse texto, é possível perceber que o conceito de educação alimentar e nutricional nas escolas demanda um aporte conceitual e técnico pelos vários sujeitos envolvidos. É mais que oferecer pontualmente atividades relativas ao tema alimentação. Nessa perspectiva, parece constituir-se um conjunto de ações pedagógicas, normativas e culturais, que se desenha nos vários espaços, como a universidade, a prefeitura, a secretaria de educação, de saúde e abrange a reflexão e a prática dos vários atores integrados a estes campos. Extrapola a sala de aula e as atividades pedagógicas desenvolvidas com os estudantes. Torna-se parte das polí- ticas locais e ocupa espaço na agenda das políticas sociais.

Vista desse ponto, a educação alimentar e nutricional favorecerá ao estudante uma aproximação com as várias informações que existem a respeito do tema alimentação e nutrição e permitirá que o estudante seja e sinta-se parte da política que normatiza e sustenta esse tema. Se sistematizadas, estas ações educativas poderão proporcionar ao estudante a construção dos conhecimentos que o instrumentalizarão a fazer suas escolhas - sobretudo na apropriação do direito humano de uma alimentação adequada -, julgar o que ouvirá na mídia e atuar de forma autônoma diante das várias alternativas que se apresentam no seu contexto. Isso parece concretizar a síntese de Paulo Freire: a leitura da escrita só tem sentido se favorecer a leitura do mundo.

\section{Considerações finais}

Ainda são inúmeros os caminhos que devem ser trilhados em direção a consolidar na prática de gestores, educadores e de nutricionistas o entendimento do papel do alimento e da educação alimentar e nutricional no contexto escolar.

Em relação à formação do nutricionista, a presença de um processo de formação tecnicista orientador de uma prática de educação alimentar e nutricional centrada na relação entre alimentos e sua composição nutricional, ao se constituir em prática no espaço escolar se realizará por meio de metodologias autoritárias, tecnicistas que se inscrevem no fortalecimento da relação centrada em um único protagonista detentor do conhecimento, o nutricionista, o que transforma esta prática em maçante tanto para estudantes quanto para professores que dela buscam participar.

Percebe-se a importância de superar esta concepção de formação, principalmente em direção a promover a integração do conhecimento, buscando construir um processo de partilha e complementaridade entre os diferentes saberes que envolvem o alimento e a alimentação, e que, indiscutivelmente, se fazem presentes por meio dos diversos atores que participam da educação alimentar e nutricional na escola, ou em qualquer outro espaço social.

Nesta direção, é fundamental um olhar mais atento para o processo de formação do nutricionista em direção a promover avanços com relação à compreensão da prática educativa envolvendo o alimento no espaço da escola e a relação 
desta com uma proposta de educação que situe os processos e as práticas educativas no cerne, nos anseios e nas necessidades da própria vida humana.

Também, como elemento importante para compor esta discussão, aparece a necessidade de consolidar no espaço escolar um novo entendimento de alimentação escolar que não se limite à questão da refeição fornecida com qualidade e adequação nutricional. Lamentavelmente, não é rara na prática escolar a presença de educadores que não percebem a alimentação escolar como estratégia pedagógica a restringindo ao mecânico ato de servir o alimento na escola.

Romper estes limites em direção a consolidar os espaços de facilitadores da integração entre os conhecimentos sobre educação dos educadores, com os conhecimentos sobre nutrição do nutricionista, pode ser um dos caminhos de superação dos limites que se fazem presentes tanto na escola quanto na própria formação do nutricionista e do docente pedagogo ou licenciado. Esta questão aponta como fundamental a constituição de espaços de formação continuada que possibilitem a promoção sistemática destas ações no âmbito dos currículos escolares, contemplando o disposto na política de alimentação escolar, que qualifica a oferta de alimentos na escola precedida, concomitante e sucedida por ações educati- vas sobre alimentação em todas as suas dimensões, inclusive a nutricional.

Importante registrar neste espaço as conquistas que na atualidade tem se verificado em relação à constituição e à implementação de uma Política Nacional de Educação Alimentar e Nutricional, na perspectiva da realização do Direito Humano a Alimentação Adequada e Saudável. Nesta discussão, encontram-se associados diferentes Ministérios como os da Educação, Saúde, Desenvolvimento Social, instâncias do controle social ligadas à alimentação e à nutrição tais como o Conselho Nacional de Segurança Alimentar e Nutricional (CONSEA), a Associação Brasileira de Nutrição (ASBRAN), entre outras que se uniram para pensar tal política em direção a efetivar ações intersetoriais em todos os âmbitos.

Outros elementos se associam aos que aqui são apontados. Mas essa discussão encontra-se longe de receber um ponto final. Antes sim, expressa reticências, no sentido de que há muito mais a ser dito, escrito, discutido e praticado. Essas reticências devem traduzir-se em tempos e espaços de reflexão e ação permanentes em direção a possibilitar que a polifonia das vozes dos diversos atores envolvidos qualifique e se traduza em uma integral, efetiva, instrumentalizadora e cidadã educação para todos, rumo à emancipação e à autonomia de nossa gente.

\section{Colaboradores}

NVS Barbosa, NMV Machado, MCV Soares e ARR Pinto participaram igualmente de todas as etapas de elaboração do artigo. 


\section{Referências}

1. Brasil. Lei no 11947 de 16 de junho de 2009. Dispõe sobre o atendimento da alimentação escolar e do programa dinheiro direto na escola aos alunos da educação básica. Diário Oficial da União 2009; 17 jun.

2. Santos LAS. Educação alimentar e nutricional no contexto da promoção de práticas alimentares saudáveis. Rev Nutr 2005; 18(Supl. 5):681-692.

3. Carvalho MCVS. Estilos naturais: uma bricolagem alimentar no Brasil urbano. [tese]. Rio de Janeiro: Instituto de Medicina Social, Universidade do Estado do Rio de Janeiro; 2009.

4. Lapassade G. Groupes, organisations et institutions. Paris: Gauthier-Villar; 1970.

5. Lobrot M. Pedagogia institucional: la escuela hacia la autogestión. Buenos Aires: Humanitas; 1966.

6. Bourdieu P. O senso Prático. Petrópolis: Vozes; 2009.

7. Martins AM. Autonomia da escola: a (ex)tensão do tema nas políticas públicas. São Paulo: Cortez; 2002.

8. Freire P. Pedagogia da autonomia: Saberes necessários à prática educativa. São Paulo: Paz e Terra; 1996.

9. Bourdieu P. O poder simbólico. Lisboa: Difel; 1989.

10. Freire P. Pedagogia do oprimido. 30a Edição. São Paulo: Paz e Terra; 1987.

11. Libâneo JC. Adeus professor, adeus professora? Novas exigências educacionais e profissão docente. 10a Edição. São Paulo: Cortez; 2007.

12. Giroux H. Cruzando as fronteiras do discurso educacional, novas políticas em educação. Porto Alegre: Artes Médicas Sul; 1999.

13. Freire P. Pedagogia da esperança, um reencontro com a Pedagogia do oprimido. Rio de Janeiro: Paz e Terra; 1992.

14. Scavino S, Candau VM. Educação em direitos humanos: temas, questões e propostas. Petrópolis: DP et Alli Editora; 2008.
15. Luz MT. Fondéments Ideologiques de la Méthode Structurell - Fonctionnelle. [dissertação]. Bélgica: Universidade Católica de Louvain; 1969.

16. Carvalho MCVS, Luz MT, Prado SD. Comer, alimentar e nutrir: categorias analíticas instrumentais no campo da pesquisa científica. Cien Saude Colet 2011; 16(Supl. 1):155-163.

17. Instituto Nacional de Estudos e Pesquisas Educacionais Anísio Teixeira (Inep). Censo Escolar: dados finais censo escolar educação básica 2011. [acessado em 2012 jul 25]. Disponível em: http://portal. inep.gov.br/basica-censo

18. Brasil. Lei 11.947 de 16 de junho de 2009. Dispõe sobre o atendimento da alimentação escolar e do Programa Dinheiro Direto na Escola aos alunos da educação básica; altera as Leis nos 10.880, de 9 de junho de 2004, 11.273, de 6 de fevereiro de 2006, 11.507, de 20 de julho de 2007; revoga dispositivos da Medida Provisória no 2.178-36, de 24 de agosto de 2001, e a Lei no 8.913, de 12 de julho de 1994; e dá outras providências. Diário Oficial da União 2009; 17 jun.

19. Barbosa NV. Currículo em verso e em prosa. Espírito Santo: Ed. Exlibris; 2006.

20. Pacheco JA. Escritos curriculares. São Paulo: Cortez; 2005.

Artigo apresentado em 20/09/2012

Aprovado em 27/10/2012

Versão final apresentada em 30/11/2012 
